\title{
STRESS ANALYSIS OF LAP JOINTS WITH EMBEDDED COVER PLATE
}

\author{
BAHATTIN İŞCAN \\ Department of Mechanics, Vocational School of Higher Education, \\ Batman University, Batman 72060, Turkey, \\ e-mail: bahattin.iscan@batman.edu.tr
}

[Received 21. November 2014. Accepted 15 June 2015]

\begin{abstract}
In this study, the effects of the bonding joints that are partly embedded in the adherent on the tensile behaviour of reinforcing plate adhesive joint have been investigated by $2 \mathrm{D}$ finite element method. In the study, the SBT 9244 material was used as the adhesive, and the adherent was the AA2024-T3 material. Three different models were built for the height of the embedded part in the adherent (a) and five models for the length of the embedded part (b), while three models were built for the total overlap length (c). Results showed that with the increase of the height of the embedded part and total overlap length, the strength of the joint was considerably increased. The increase of the length of the embedded part was initially led to an increase in the strength of the joints but after 0.25 value of the $\mathrm{b} / \mathrm{c}$ the strength was reduced.

KEY WORDS: Joint design, repair, finite element method, adhesive.
\end{abstract}

\section{Introduction}

In the adhesive joints, the failure usually starts at edges of the adhesive layer. The reason for this is the higher peeling stress values that occur at the edge of the adhesive region [1]. Constructions are made up with welding, bolts, rivets and methods such as friction or with hybrid connection, which is their combination [2]. As for the adhesive joints, in order to reduce the stresses, methods such as the single overlap, double reinforcement overlap and angled overlap constructions are used. There is another type of the bonding application that constructed as embeedding the covered plates by joinning them with adhesive materials. The embeedded cover plates bonding models may have wide usage areas in aerospace, automotive and even in building construction.

Sayman [3] has investigated elasto-plastic strain behaviour of the adhesive bond analytically and numerically. As a result of the study, it was 
found that the high shear stress occurs in the thin plate, while increase of the plate thickness reduces the shear stress. Tang et al. [4] have experimentally and numerically studied the static and fatigue behaviour of combining the thin composite plates with adhesive. Results showed that the failure begins at the interface of the adhesive with the adherent. You et al. [5] investigated the stress behaviour of the combination of junction regions of the angled steel adherent with adhesive by the elasto-plastic finite element method. The failure load was found to be higher when the tip angle of the model was $7^{\circ}$. Özer and Özer [6] have investigated tensile behaviour of the double overlapping adhesive joints with the finite element method for four different overlap lengths. In order to reduce the effect of the peeling, stress occurs at end regions of the adhesives. At the end regions, soft adhesives were used, while the hard adhesives were used at mid regions. It was found that using hybrid adhesive models has significantly better tensile behaviour than using a single type of adhesive models. Adin [7] has experimentally and numerically investigated the effects of the thrust angle on the stress in the overlap joints. The researcher has reported the increase in thrust angle with reduction in the failure load by using epoxy-based adhesive material 580 Atlac. Haghpanah et al. [8] investigated the mechanical properties of the zigzag model for adherents with single overlap adhesive joints. Results showed that the negative screwing models have lower strength values than those of positive screwing model or non-screwing models. Khalil et al. [9] has carried out a numerical study on tensile behaviour of the single overlap adhesive joints. It was found that the highest peeling and shear stress values were formed at the end regions of adhesive, and was found to improve the mechanical properties of the joints using the fiber reinforced adhesive layer instead of the usage of epoxy based adhesive. Topkaya and Solmaz [10] investigated the mechanical properties of the hybrid assembled, rivet and adhesive joints by the progressive failure analysis method. They found that the mechanical properties of the joint were enhanced with increase of the overlap distance. Derewon' ko [11] numerically and experimentally examined the stress behaviour in double-lap joints, composed of metal and composites. The researcher, using the Gurson criterion which employs hydrostatic stress sensitivity in order to research the ductile fracture in the adhesive, confirmed that the contact fraction stress between the adhesive and aluminium plate is $90 \%$ higher than the stress occurring between the adhesive and composite plate. Sadowski et al. [12] experimentally and numerically examined the behaviour of the stress of adhesive, fastener, and hybrid types of joint in double-lap joints composed of aluminium plates by using the finite element method. The researchers, observing plastic deformation in pins and aluminium plates in the performed study, confirmed that hybrid joints had 
higher tensile strength than only pin or only adhesive joints.

In this study, the effects of the bonding joints that are embedded in the adherent on the tensile behaviour of the reinforcing plate adhesive joints have been investigated by finite element method. The analyses were made by ANSYS 14, the finite element software. SBT 9244 was used as the adhesive material, while the adherent was AA2024-T3 aluminium alloy.

\section{Material and method}

The geometry and the parameters that were used in this study are given in Fig. 1. The adherent thickness was (H) $6.2 \mathrm{~mm}$, the adhesive thickness (t) was $0.2 \mathrm{~mm}$ and total length (L) was $130 \mathrm{~mm}$. Total overlap length (c) was $30,40,50 \mathrm{~mm}$, the ratio of the embedded region length to total overlap length $(\mathrm{b} / \mathrm{c})$ was $0.175,0.2125,0.25,0.2875,0.325$ and the ratio of embedded region depth to adherent height $(\mathrm{a} / \mathrm{h})$ was $0.15,0.2$ and 0.25 .

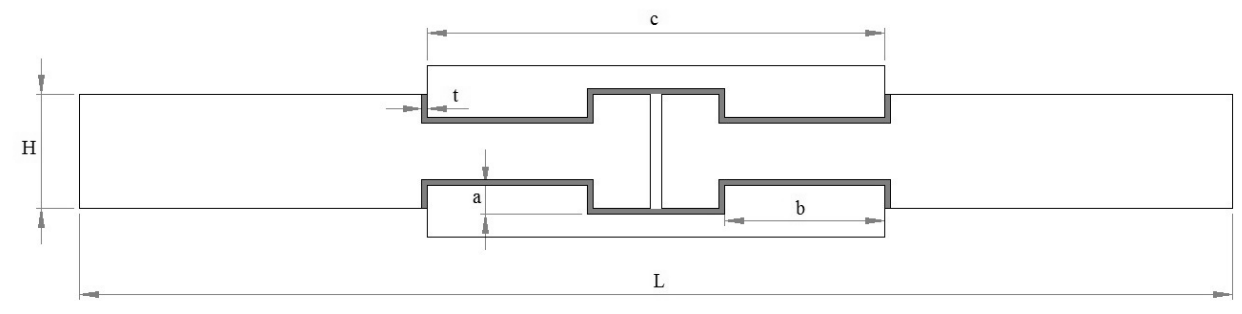

Fig. 1. The joint model

The AA2024-T3 was used as the adherent and the SBT 9244 was used as the adhesive in the samples in order to analyze the stress behaviour. The mechanical properties of the test materials are summarized in Table 1.

Table 1. Materials properties [13]

\begin{tabular}{|l|c|c|}
\hline & AA2024-T3 & SBT 9244 \\
\hline E (MPa) (Yong's Modulus) & 71875 & 62 \\
\hline$\nu$ (Poisson's Ratio) & 0.33 & 0.35 \\
\hline$\sigma^{*}(\mathrm{MPa})$ (Ultimate Strength) & 482 & 21 \\
\hline$\varepsilon^{*}(\mathrm{~mm} / \mathrm{mm})$ (Ultimate Strain) & 0.159 & 0.942 \\
\hline
\end{tabular}

Samples with different geometrical values were subjected to finite element analysis with ANSYS program. In Figure 2, the mesh characteristic of the finite element model with the overlap length of $30 \mathrm{~mm}, \mathrm{a} / \mathrm{b} 0.15$ and the $\mathrm{H} / \mathrm{C}$ ratio of 0.175 are presented. Plane 82 was used as the element type when 
the models were meshed. The element plane of 82 has 8 nodes and at each node has two degrees of freedom.
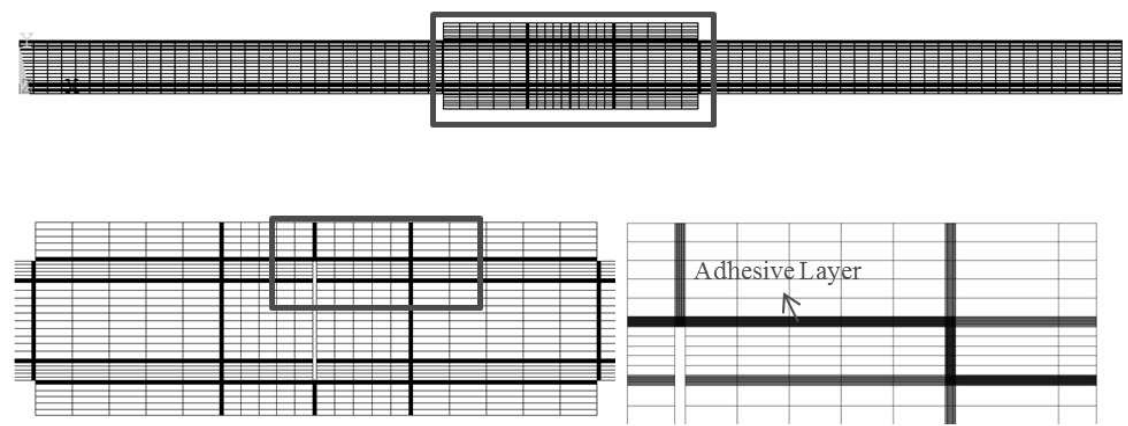

Fig. 2. The mesh structure of finite elements

The joints were subjected to the tension force and the stress analysis was carried out with finite element method. The boundary conditions of the finite element model are given in Fig. 3.

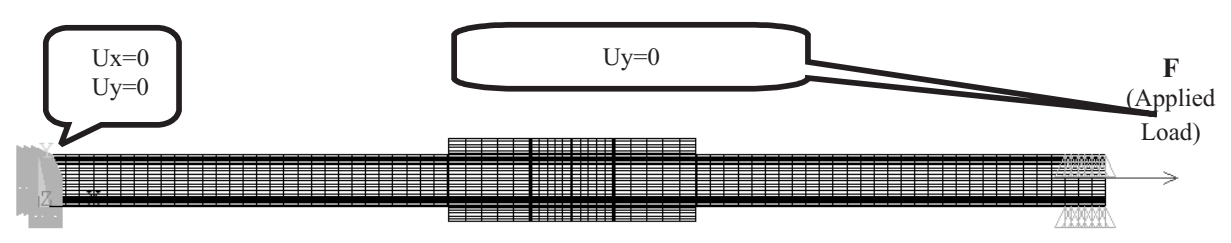

Fig. 3. Application of boundary conditions

\section{Results and discussion}

As a result of the analysis, a path defined for upper adhesive layer adherent interface in order to examine the stresses distribution that occurred in joint. The used path in order to show the stress distributions is given in Fig. 4. In order to compare the stress occurred on the joints, $6500 \mathrm{~N}$ load was applied to each joints and the stress distributions with this load are presented in Fig. 4.

In the case of the adherent width of $25 \mathrm{~mm}$, the obtained failure loads are given in Table 2. As can be seen in the Table 2, the increase of the ratio of $\mathrm{a} / \mathrm{h}$ and the total value of the overlap length resulted in an increase in the failure load. For the $\mathrm{b} / \mathrm{L}$ ratio of 0.25 , the maximum failure load was found 


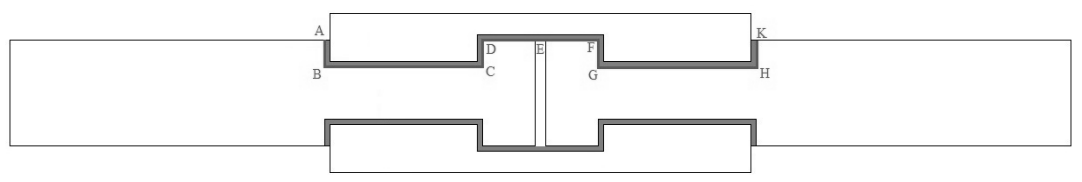

Fig. 4. The path orbit

in the model and the increase or the decrease of this ratio has reduced failure load. As the "a" value that represents the embedding amount to the adherent was increased, the failure load was increased. The reason of this is considered to be the increase of the adhesion area that is exposed to the peeling stresses. Besides, if the joint subjected to the tensile load move to the outside of the embedding patch it will try to separate. However, when the "a" height was increased the friction occurred on the vertical adhesion areas will also increase and will prevent the separation of the patches. The increase of $b$ length was initially increased with the load failure but then decreased it gradually.

Table 2. Failure loads that exist in the joints

\begin{tabular}{|l|c|}
\hline Parameter & Failure load $(\mathrm{N})$ \\
\hline$a / h=0.15$ & 6705.09 \\
\hline$a / h=0.2$ & 9507.22 \\
\hline$a / h=0.25$ & 13610.34 \\
\hline$b / c=0.175$ & 6705.09 \\
\hline$b / c=0.2125$ & 6755.13 \\
\hline$b / c=0.25$ & 6805.17 \\
\hline$b / c=0.2875$ & 6755.13 \\
\hline$b / c=0.325$ & 6705.09 \\
\hline$c=30$ & 6705.09 \\
\hline$c=40$ & 8006.08 \\
\hline$c=50$ & 9006.84 \\
\hline
\end{tabular}

In Fig. 5, influence of the variation in $a / H$ ratio on the stress distribution, which occurred in the adhesive layer is presented. It represents the peeling stress $\sigma_{x}$ values in the adhesive layer within the ranges of $\mathrm{A}-\mathrm{B}, \mathrm{D}-\mathrm{C}$, $\mathrm{F}-\mathrm{G}$ and $\mathrm{H}-\mathrm{K}$. As the highest values of $\sigma_{x}$ and $\sigma_{y}$ along side all the path were found for $\mathrm{A}-\mathrm{B}, \mathrm{C}-\mathrm{D}, \mathrm{F}-\mathrm{G}$, and $\mathrm{H}-\mathrm{K}$, it suggests that the adhesive layer begins to separate from the adherent area in the these regions. As for B-C, D-F and $\mathrm{G}-\mathrm{H}$ regions, which are parallel to the loading direction, the progression towards the middle of the region results in stress values to be decreased. It peaks at E point, and has slightly increase along the D-F horizontal curve. It 

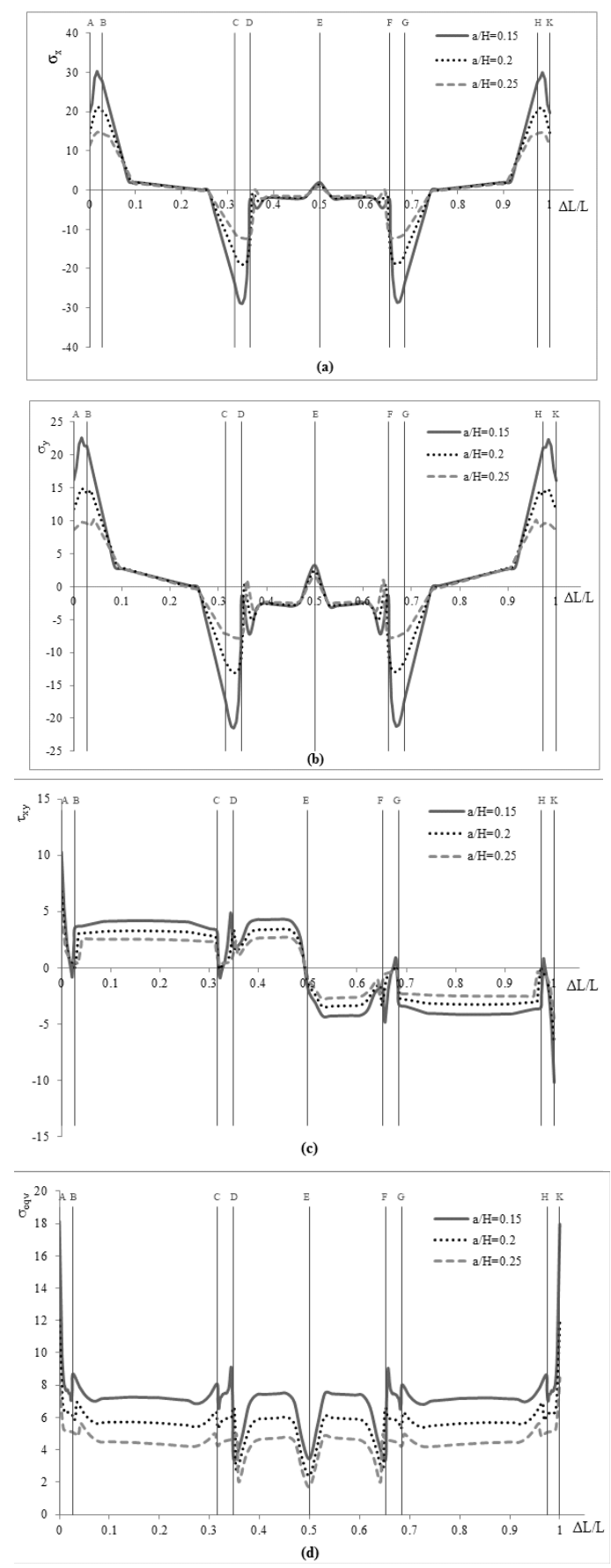

Fig. 5. The effects of variation of the $a / H$ on stress distribution 
Stress Analysis of Lap Joints with Embedded Cover Plate
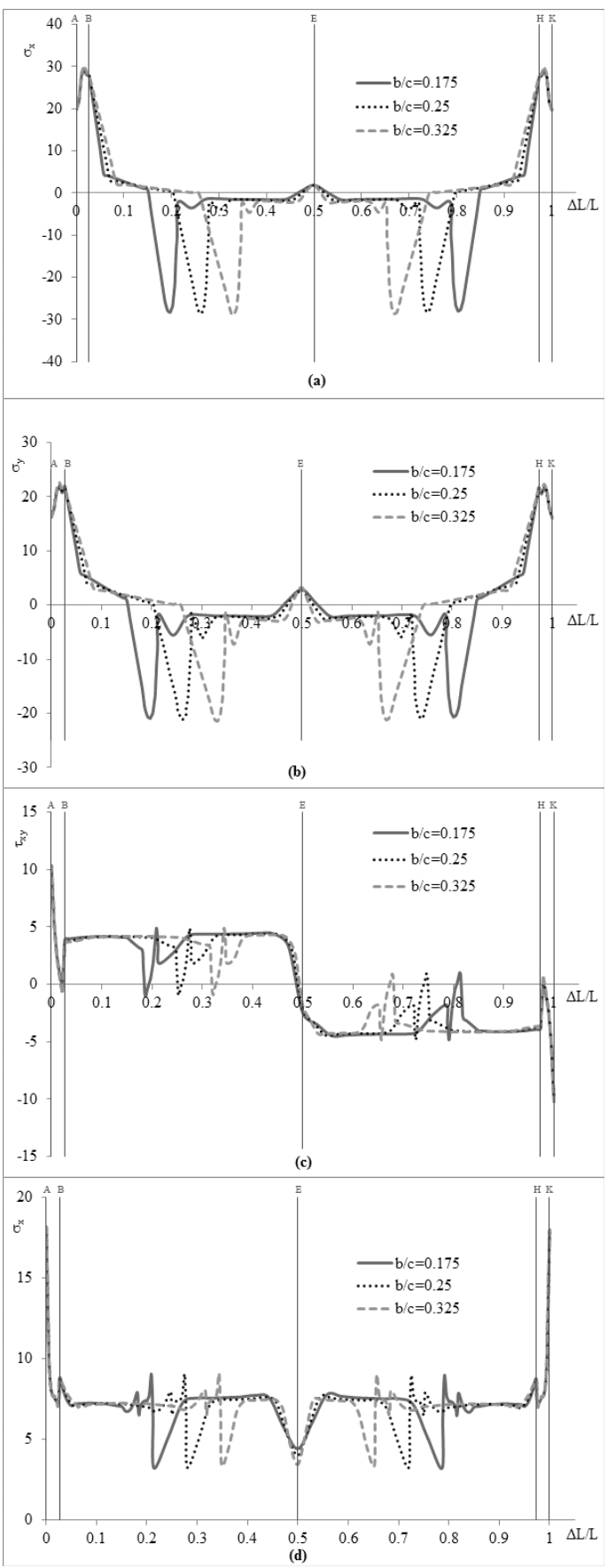

Fig. 6. The effects of the variation of the $b / c$ on stress distribution 


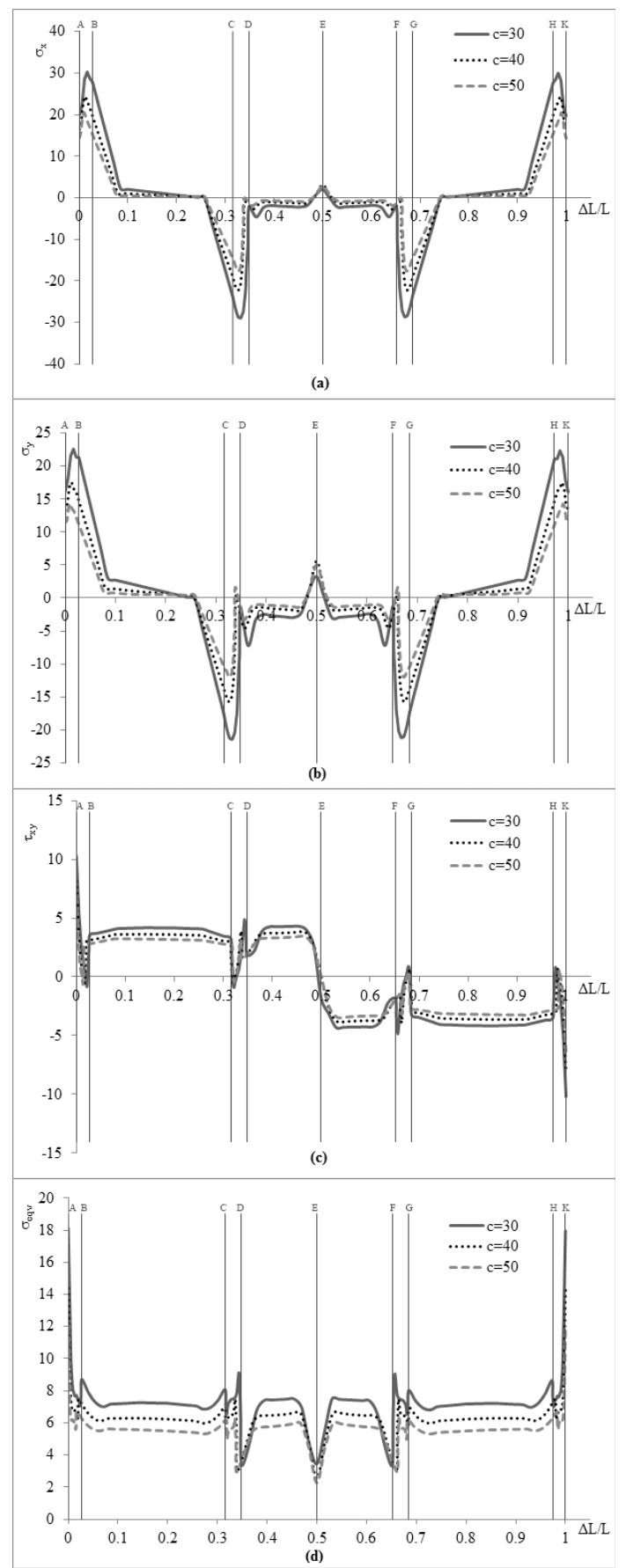

Fig. 7. The effects of overlap length (c) on stress distribution 
is considered, that the reasons are the probable gaps between two adherent and thinning the adhesive layer, due to the tensile load applied to adhesive layer. In Fig. $5 c$, the variation of the shear stress along to the adhesive layer is presented. Except for the end regions of the adhesive layer, the highest shear stress values were found to be at $\mathrm{B}-\mathrm{C}, \mathrm{D}-\mathrm{F}$ and $\mathrm{G}-\mathrm{H}$ regions. At the surroundings of the $\mathrm{E}$ point, which is at the midpoint line of the adhesive layer, the shear stress values are closed toward zero. Also, the increase in $a / H$ values reduces $\sigma_{x}, \sigma_{y}$, and $\sigma_{e q v}, \tau_{x y}$ stress values as can be seen in Fig. 5 .

The effects of variation of the $b / c$ on the stress distribution along the adhesive layer are presented in Fig. 6. The stress values, which are similar to those in Fig. 5, with increase in the embedded region, have shifted towards the middle of the adhesive layer. However, any changes in tensile behaviour were not observed according to the mentioned points in Fig. 4. As regards the failure load in Table 2, the effect of $b / c$ on the failure load is small, as can be observed. The same situation is valid for the graphs, that are presented in Fig. 6.

The effects of overlap length (c) on stress are provided in Fig. 7. The increase in length appears to reduce the stress. The highest von Misses stresses were occurred on the edges. This result shows that the failure will start at the edges of the overlap length. The reason of the higher von Misses stresses at the $\mathrm{A}-\mathrm{B}$ and $\mathrm{K}-\mathrm{H}$ vertical adhesion areas, as well as the starting of the failure at these areas is that the adhesive at these areas was subjected to highest deformation [14-16].

\section{Conclusion}

In the present study, AA2024-T3 alloy was connected with the embedded cover plate and the effects of embedding height, length and overlap length on stress behaviour have been investigated. The results of the analysis are presented, as follows:

- The increase in total overlap length has reduced the stress values.

- Increasing of the height of the embedded plate, resulted in decreased stress values in the adhesive layer. In spite of the increase of the vertical adhesion areas, the reason of the stress reduction is the resistance of the embedded plates to separation. However, it should be noted that the connected adherents may be weakened.

- Provided that total overlap area remains constant, the increase in embedded length, has not considerably affected on the stress values.

- The failure initially occurred at vertical adhesion areas for all the joints. The reason of this is the increase of the peeling stresses at the vertical adhesion areas. 


\section{REFERENCES}

[1] Temiz, Ş. J. Application of Bi-adhesive in Double-strap Joints subjected to Bending Moment. Adhesion Sci. Technol., 20 (2006), 1547-1560.

[2] Da Silva, L. F. M., A. Pirondi, A. Ö. Chsner. Hybrid Adhesive Joints, Heidelberg, Springer, 2011.

[3] Sayman, O. Elasto-plastic Stress Analysis in an Adhesively bonded Single-lap Joint. Compos. Part B-Eng., 43 (2012), 204-209.

[4] Tang, J. H., I. SRidhar, N. SRIkanth. Static and Fatigue Failure Analysis of Adhesively bonded Thick Composite Single Lap Joints. Comp. Sci Technol., 86 (2013), 18-25.

[5] You, M., X. Li, X. Zheng, S. Yu, G. Li, D. Sun. A Numerical and Experimental Study of Preformed Angle in the Lap Zone on Adhesively bonded Steel Single Lap Joint. Int. J. Adhes. Adhes., 29 (2009), 280-285.

[6] Özer, H., Ö. Öz. Three Dimensional Finite Element Analysis of Bi-adhesively bonded Double Lap Joint. Int. J. Adhes. Adhes., 37 (2012), 50-55.

[7] Adin, H. The Investigation of the Effect of Angle on the Failure Load and Strength of Scarf Lap Joints. Int. J. of Mech. Sci., 61 (2012), 24-31.

[8] Haghpanah, B., S. Chiu, A. Vaziri. Adhesively Bonded Lap Joints with Extreme Interface Geometry. Int. J. Adhes. Adhes., 48 (2014), 130-138.

[9] Khalili, S. M. R., S. Khalili, M. R. Pirouzhashemi, A. Shokuhfar, R. K. Mittal. Numerical Study of Lap Joints with Composite Adhesives and Composite Adherents subjected to In-plane and Transverse Loads. Int. J. Adhes. Adhes., 28 (2008), 411-418.

[10] Solmaz, M. Y., T. Topkaya. Progressive Failure Analysis in Adhesively, Riveted, and Hybrid Bonded Double-Lap Joints. J. Adhesion, 89 (2013), 822-836.

[11] Derewon'Ko, A. Prediction of the Failure Metal/composite Bonded Joints. Comp. Mater. Sci., 45 (2009), 735-738.

[12] Sadowski, T., P. Golewski, E. Zerzeka-Raczkowska. Damage and Failure Processes of Hybrid Joints: Adhesive Bonded Aluminium Plates Reinforced by Rivets. Comp. Mater. Sci., 50 (2011), 1256-1262.

[13] Aydin, M. D., Ş. Temiz, A. Özel. Effect of Curing Pressure on the Strength of Adhesively Bonded Joints. J. Adhesion, 83 (2007), 553-571.

[14] Bavi, O., N. Bavi, M. Shishesaz. Geometrical Optimization of the Overlapin Mixed Adhesive Lap Joints. J. Adhesion, 89 (2013), 948-972.

[15] HuA, Y., L. Gu, M. Trogdon. Three-dimensional Modelling of Carbon/epoxy to Titanium Single-lap Joints with Variable Adhesive Recess Length. Int. J. Adhes. Adhes., 38 (2012), 25-30.

[16] Karachalios, E. F., R. D. Adams, L. F. M. Da Silva. Single Lap Joints loaded in Tension with High Strength Steel Adherents. Int. J. Adhes. Adhes., 43 (2013), 81-95. 